\title{
Ticari İçten Yanmalı Bir Motorun Hava Emiş Sistemi Tasarımı
}

\author{
*1 Orhan Pehlivan \\ *1TOFAŞ, Ar-Ge Direktörlüğü,Motor Transmisyon ve Kontrol Sistemleri Müdürlüğü, Bursa,Türkiye
}

\section{Özet:}

İçten yanmalı motorlarda kullanılan hava emiş sisteminin temel amacı, motordan istenilen performansı elde etmek için gereken temiz havayı sağlamaktır. Özellikle, motorda yanma için gerekli olan oksijen, hava emiş sistemi tarafindan elde edilen temiz havadan sağlanır. Bu nedenle, motora verilen havanın temizliği ve akış kalitesi motor performansını etkiler. Motora verilen havanın taşınması ve temizlenmesi hava emiş sistemi ile gerçekleştirilir. Bu çalışmada, müşteri tanımlama parametrelerini, ürün geliştirme sürecini, sistem parametrelerinde optimizasyonu ve sanal doğrulamalarını uygulayarak tamamlanmış bir hava emiş sistemi tasarım süreci baştan sona açıklanmıştır. Bu süreçte, teşhis etme, tanımlama, geliştirme, optimize etme, doğrulama (IDDOV) dizisini temel alan Altı Sigma Tasarım (DFSS) metodolojisi kullanılmıştır.

Anahtar Kelimeler: Hava emiş sistemi, Altı Sigma Tasarım, IDDOV

\section{Air Intake System Design of Commercial Internal Combustion Engine}

\begin{abstract}
:
The main purpose of the air intake system used in internal combustion engines is to provide the fresh air needed to obtain the required performance from the engine. In particular, the oxygen required for combustion in the engine is supplied from the fresh air obtained by the air intake system. Therefore, the cleanliness and flow quality of the air delivered to the engine affects the engine performance. The transport and cleaning of the air delivered to the engine is carried out with the air suction system. In this study, completed air intake system design was explained from the beginning to the end, implementing the customer definition parameters, product developing sequence, optimization on the system parameters and virtual verifications. In this process, Design for Six Sigma (DFSS) methodology was used based on the identify, define, develop, optimize, verify (IDDOV) sequence.
\end{abstract}

Keywords: Air intake system, Design for Six Sigma, IDDOV

\section{Giriş}

İçten yanmalı motorların ihtiyaç duyduğu havanın elde edilmesi amacıyla oluşturulan sistem hava emiş sistemidir. Motorun diş ortamından veya atmosferden emilen taze hava, motora ulaştırılmadan önce hava filtresi yardımıyla temizlenir. Temizlenme işlemi, hava filtresinin de içinde yer alığı bir kutuda gerçekleşir. Bu kutuya hava filtre kutusu da denilir. Hava filtre kutusundan çıkan temiz hava borular vasıtasıyla motora ulaştırılır. Genel olarak, havanın temizlenmeden önce taşındığı kısma, kirli hava emiş kısmı; havanın temizlendikten sonraki kısmında da temiz hava emiş kısmı adlandırması yapılır.

* Corresponding author: Address: TOFAŞ Türk Otomobil Fabrikas1 A.Ş., AR-GE Departman1, İstanbul Cad., No:574, Osmangazi, Bursa, TURKEY. E-mail address: orhan.pehlivan@ @ofas.com.tr, Phone: +902242610350 
Filtre kutusunun içinde yer alan filtre elemanlarının, dış ortamdan gelecek su etkisinden korunması gereklidir. Filtre elamanı öncesinde yer alan kirli hava emiş kısmının tasarım yapısı ile filtre elamanına suyun ulaşması engellenir. Özellikle dış ortamdan havanın ilk alındığı eleman olan şnorkelin giriş yüksekliği suyun filtreye girmemesi için doğru pozisyona yerleştirilir.

Hava emiş sisteminin diğer bir amacı da motorun hava emme gürültüsünü uygun seviyeye getirmektir. Araç kullanıcısı veya yolcusu açısından motorun oluşturduğu hava emme gürültüsü seviyesi, araç konforu için önemli bir kriterdir. Oluşan gürültünün, kullanıcıyı ve müşteriyi rahatsız etmeyecek seviyelerde olması gerekmektedir. Hava emiş sistemi ile birlikte motor öncesinde bir akış yolu ve hacmi oluşturulmaktadır. Oluşturulan bu hava emiş sistemi düzeninde, tasarıma bağlı olarak basınç değişimleri ve kayıpları meydana gelmektedir. Bu değişim ve kayıplara paralel olarak gürültü seviyelerinde de iyileştirmeler elde edilmektedir. Tasarımı oluşturan parçaların genel olarak geometrilerine, büyüklüklerine ve malzeme özelliklerine göre hava emiş sisteminin basınç değişimleri, dolayısıyla da gürültü özellikleri de değişmektedir. Hava emiş sistemi için seçilen tasarım hem motor öncesi basınç kaybı hem de motor emme gürültüsü özellikleri açısından etkili bir oluşumdur [1].

Motor hava emme gürültüsünün düzenlenmesinde, hava emiş sisteminde oluşan basınç kayıları önemli bir etkendir. Diğer taraftan, motordan beklenen maksimum gücün elde edilmesi ve motorun istenilen devir aralığında verimli olarak çalışması için motora giren temiz hava sistemi ile motordan çıkan egzoz sistemi arasında basınç dengesi olması gerekmektedir. $\mathrm{Bu}$ dengenin korunması amacıyla, her bir motor için olması gereken en büyük hava emiş sistemi kaybı belirlenmektedir. Hava emiş sistemleri de belirlenen bu basınç kaybını aşmayacak şekilde tasarlanmaktadır. Motor kalibrasyonları da hava emiş sistemindeki ve egzoz sistemindeki basınç kaybı değerlerine göre yapılmaktadır. Eğer basınç kayıpları için belirlenen en büyük hedef değerler aşılırsa, motorun yanma rejimi etkilenmektedir. $\mathrm{Bu}$ durumda da motordan istenilen güç değerleri elde edilememektedir. Yakıt kullanımı ve emisyon değerleri olumsuz etkilenmektedir [2].

Hava emiş sistemi tasarımında, kullanıcılar veya yolcular için önemli etken olan gürültü kontrol altına alınmalıdır. Gürültü ile ters orantılı olarak değişen basınç kaybı da motorun uygun çalışma şartlarının sağlanması için belirlenen en büyük hedef değerlerinin altında olmalıdır. Diğer bir değişle, yapılacak hava emiş sistemi hem gürültü hem de basınç kaybı verilerine göre optimum bir düzeyde oluşacak şekilde tasarlanmalıdır.

Hava emiş sistemi tasarımında, gürültü ve basınç kaybı haricinde farklı etmenler de dikkate alınmalıdır. Hava emiş sistemi temiz hava emiş borusu aracılığıyla motora bağlanmaktadır. Motorun hareketleri de hava emiş sistemini etkilemektedir. Hem araç hareketleri hem de motor hareketleri göz önüne alınarak, hava emiş sistemi ile çevre parçalar arasında birbirlerine zarar vermeyecek mesafeler birakılmalıdır.

Hava emiş sistemi, 1sı kaynağı oluşturan motor veya egzoz sistemi parçaları ile yakın mesafelere yerleşebilmektedir. Hava emiş sistemi için seçilen malzemeler, aracın çalışma koşulları belirlenerek oluşacak yüksek sıcaklıklara dayanımlı olacak şekilde belirlenmelidir. Ayrıca, tasarım ve malzemeler aracın çalışma koşullarına dayanım gösterebilmelidir. 
İçten yanmalı bir motorun hava emiş sistemi için gerekli kıstaslar göz önüne alınarak yeni bir tasarım, detayları ile bu çalışma yardımıyla oluşturulmuştur. Çalışma bütününde, Tasarım için Altı Sigma (DFSS) yaklaşımından yararlanılmıştır. Sistemin gereksinimlerinin belirlenmesinden, oluşturulan yeni tasarımın doğrulanmasına kadar farklı aşamalarda incelemeler yapılarak optimum bir tasarım elde edilmiştir. En uygun tasarımın seçilmesi için basınç kaybı ve gürültü seviyeleri analizlerinden faydalanılmıştır. Tasarım süreçleri içerisinde yapılan basınç ve gürültü analizlerinde 1-D simülasyon yöntemleri kullanılmıştır. Elde edilen tasarım, CFD ve yapısal analiz sonuçları ile doğrulanmıştır.

\section{Hava Emiş Sisteminin Tanımlanması ve Tasarım Sınırlarının Belirlenmesi}

Hava emiş sistemi için yapılan bu çalışmada ana hedef olarak sistemin en uygun basınç kaybına ve ses seviyesine sahip olması amaçlanmıştır. Tasarım içim hedefler ve detaylar belirlendikten sonra, tasarımın geliştirilmesi ve doğrulamaları yapılmıştır. İlk olarak hava emiş sistemde yer alan bölümlerin işlevleri incelenmiştir.

\subsection{Hava emiş sisteminin fonksiyonel yapısı}

Hava emiş sistemi genel olarak iki bölüme ayrılabilir. Bu bölümlerden ilki atmosferden veya diş ortamdan alınan taze havanın temizlenmeden önceki durumunu kapsayan kirli hava emiş kısmıdır. Diğer bölüm ise kirli havanın filtrelenmesi sonucu oluşan temiz havayı, motora ulaştıran kısımdır. Kirli hava emiş kısmında, atmosferden havanın alınmasına yardımcı olan şnorkel parçası, kirli havayı filtreye ulaştıran boru ve filtre kutusunun temizlenmemiş havayı kapsayan kısmıdır. Diğer kısımları temiz hava emiş kısmı olarak adlandırabiliriz. Aşağıda yer alan Şekil 1'de genel bir hava emiş sistemi gösterilmişidir.

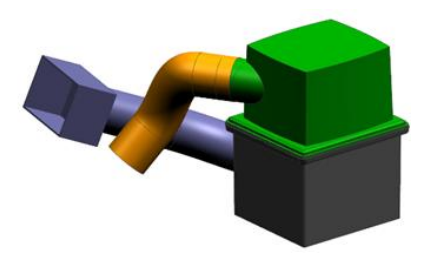

Şekil 1. Hava emiş sistemi genel görünüşü

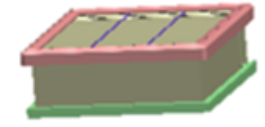

Şekil 2. Örnek filtre elemanı

Hava emiş sistemi yardımıyla, motora taze ve temiz hava gönderilirken oluşan basınç kaybı değeri ve gürültü seviyesi belirlenen sınır değerlerin altında olmalıdır. Temel fonksiyonel beklenti basınç kaybı ve gürültü seviyesi değerleri olarak düşünülebilir. Ayrıca, hava emiş sisteminden farklı beklentiler de bulunmaktadır. Beklentisi olan her bir yapıtı, hava emiş sisteminin müşterisi olarak adlandırabiliriz. Bu bağlamda, hava emiş sisteminin dört temel kıstası, bir başka değişle de müşterisi bulunmaktadır. Bunlar, aracın motoru, aracın sahibi (araçta seyahat edecek kitleyi kapsamaktadır), aracın montaj yapılacağı süreç ve aracın kalite kriterleridir.

Aracın motoru için en önemli kıstaslardan biri, hava emiş sistemi kaynaklı oluşacak basınç kaybıdır. Ayrıca, hava emiş sistemi yardımıyla temizlenen hava motorun talep ettiği debiye ve 
uniformitiye ulaştırılmalıdır.

- $\quad$ Araç sahipleri, kullanıcıları ve yolcular için önemli etkenler, hava emiş sisteminden gelecek gürültüdür. Diğer önemli bir beklenti de hava emiş sisteminin içine su girişi olmamasıdır. Eğer filtre elemanı sudan etkilenirse fonksiyonunu tam olarak yerine getiremez. $\mathrm{Bu}$ durum motora verebileceği olumsuz etki sebebiyle hem araç sahibi hem de motor için istenilmeyen durumdur.

- $\quad$ Aracın montaj yapılacağı süreç için önemli beklenti, sistemin kolay montaj edilebilmesidir. Buradaki önemli unsurlardan biri hava emiş sistemi ile çevre parçalar arasındaki yeterli yakınlıklardır. Ayrıca, sistem hem kolay montaj edilmeli hem de sökülmelidir.

Kalite açısından bakıldığında sistemin fonksiyonelliğini tam olarak yerine getirmesi beklenmektedir. Ayrıca, kullanılan malzemelerin çalışma şartlarındaki sıcaklık değişikliklerine dayanması ve hava filtre kutusunun mukavemet açısından dayanıklı olması beklenmektedir.

\subsection{Tasarım sınırlarının belirlenmesi}

Hava emiş sisteminin tasarım sınırlarının belirlenmesinde, yukarıda da açılanan dört temel kıstas ele alınmıştır. Bu kıstaslar için hedef değerler belirlenmiştir. Motor için, geri basınç ve akış uniformluk oranı sınırları belirlenmiştir. Araç sahipleri, kullanıcıları ve yolcular için gürültü seviyesi hedefi tanımlanmıştır. Aracın montaj süreci için çevresel parçalar ile olması gereken en düşük mesafeler belirlenmiştir. Kalite beklentileri açısından, sistemin dayanması gereken en yüksek sıcaklılar ve filtre kutusunun dayanım sınır açıklanmıştır. Tasarım sınırları ile ilgili beklentiler Tablo 1 ile açıklanmıştır.

Tablo 1. Tasarım sinırları

\begin{tabular}{|c|c|c|}
\hline Gereklilikler & Kisitlar & Hedef \\
\hline \multirow{3}{*}{ Motor } & Geri Basınç & $<\mathrm{a}+3,5 \mathrm{kPA}$ \\
\hline & Akış- Uniformite Indeksi & $>a+0,92$ \\
\hline & Debi & $<\mathrm{b}+500 \mathrm{~kg} / \mathrm{h}$ \\
\hline \multirow{5}{*}{$\begin{array}{c}\text { Araç sahipleri, } \\
\text { kullanıcılar, } \\
\text { yolcular }\end{array}$} & \multirow{4}{*}{ Gürültü Seviyesi } & $\mathrm{c}+91 \mathrm{~dB}(\mathrm{~A}) @ 1000 \mathrm{RPM}$ \\
\hline & & c+94dB(A)@3000 RPM \\
\hline & & c+97dB(A)@4000 RPM \\
\hline & & $\mathrm{c}+100 \mathrm{~dB}(\mathrm{~A}) @ 5000 \mathrm{RPM}$ \\
\hline & Su Girişi Korunma Seviyesi & $\begin{array}{c}\text { Snorkel Hava Giriş Yüksekliği } \\
>\text { b }+300 \mathrm{~mm}+\text { Su Hattı } \\
\text { yüksekliği }\end{array}$ \\
\hline \multirow{2}{*}{ Montaj Süreci } & Çevre Parçalar ile Yakınlık & $>\mathrm{b}+40 \mathrm{~mm}$ \\
\hline & Montaj & Takılıp, Sökülebilmeli \\
\hline \multirow{3}{*}{ Kalite } & Malzeme Dayanımı & $<\mathrm{a}+150^{\circ} \mathrm{C}$ \\
\hline & $\begin{array}{c}\text { Hava Filtre Kutusu } \\
\text { Dayanımı }\end{array}$ & > b+280 Hz@1.Mod \\
\hline & Fonksiyonel & $\mathrm{R} / 100<\mathrm{c}+0.02 @ 12$ Months \\
\hline
\end{tabular}

\section{Hava Emiş Sisteminin Tasarımın Geliştirilmesi}

Tasarım sisteminin seçilmesi sürecinin bir diğer aşamasında da benzer araçların incelemeleri ve karşılaştırmaları yapılmıştır. Yapılan incelemeler sonucunda, bu sisteminin kullanılacağı araca uygun motor yerleşimi sebebiyle tek tip hava emiş kutusu ve kutuya uygun filtre elemanı 
kullanılması uygun görülmüştür. Analizlerde hava emiş kutusunun yapısı ile ilgili bir değişsen kullanılmamıştır. Fakat, filtrenin hava emiş kutusu içerisinde pozisyonu değişkenler içerisinde yer almıştır. Motor pozisyonu yerleşimi ve çevresel parçalar ile olması gereken mesafeler sebebiyle, hava emiş sistemi borularının uzunluklarının da sabit olması gerekmektedir. Kullanılacak malzemeler plastik türevleri ve kauçuk olarak belirlenmiştir. Malzemeler değişken olarak değerlendirilmemiştir. Değişkenler, kirli hava emiş borusu çapı ve et kalınlığı, temiz hava emiş borusu çapı ve et kalınlığı, şnorkel giriş ağzı giriş alanı olarak belirlenmiştir. Aşağıdaki Tablo 2'de değişkenler ve değerleri gösterilmiştir.

Tablo 2. Tasarım değişkenleri

\begin{tabular}{|c|c|c|c|c|c|}
\hline Parça Tanımı & Parça Görseli & Değişken 1 & Değişken 2 & Değișken 3 & Değişken 4 \\
\hline $\begin{array}{l}\text { Kirli Hava Emiş Borusu } \\
\text { Çapı }(\mathrm{mm})\end{array}$ & & $d+75$ & $\mathrm{~d}+80$ & $d+85$ & $d+90$ \\
\hline $\begin{array}{l}\text { Temiz Hava Emiş } \\
\text { Borusu Çapı }(\mathrm{mm})\end{array}$ & & $d+65$ & $\mathrm{~d}+70$ & $\mathrm{~d}+75$ & $\mathrm{~d}+80$ \\
\hline $\begin{array}{l}\text { Şnorkel Giriş Alanı } \\
\left(\mathrm{mm}^{\wedge} 2\right)\end{array}$ & & $e+6500$ & $\mathrm{e}+8000$ & $e+9500$ & $e+11000$ \\
\hline $\begin{array}{l}\text { Kirli Hava Emiş Borusu } \\
\text { Kalınlığ1 }(\mathrm{mm})\end{array}$ & 11 & $f+2$ & $f+3$ & & \\
\hline $\begin{array}{l}\text { Temiz Hava Emiş } \\
\text { Borusu Kalınlığ }(\mathrm{mm})\end{array}$ & $\theta$ & $f+2$ & $f+3$ & & \\
\hline
\end{tabular}

Tablo 2'deki değişkenler kullanılarak Taguchi metodu yardımıyla 16 farklı tasarım konsepti oluşturulmuştur [3]. Oluşturulan tasarım konseptleri Tablo 3' de yer almaktadır. Belirlenen konseptler, karar matris metodu oluşturularak Pugh yöntemi yardımıyla değerlendirilmiştir [4]. Burada, çok seçenekli bir tasarım setinden, belirlenen farklı kriterler yardımıyla en uygun tasarım konseptinin oluşturulması amaçlanmıştır. Oluşturulan bu karar matrisi aşağıdaki gibi Tablo 4 ile gösterilmiştir.

Tablo 3. Tasarım konseptleri

\begin{tabular}{|c|c|c|c|c|c|}
\hline $\begin{array}{c}\text { Konsept } \\
\text { Numaras1 }\end{array}$ & $\begin{array}{c}\text { Kirli Hava } \\
\text { Emiş Borusu } \\
\text { Çap1 (mm) }\end{array}$ & $\begin{array}{c}\text { Temiz Hava } \\
\text { Emiş Borusu } \\
\text { Çap1 }(\mathrm{mm})\end{array}$ & $\begin{array}{c}\text { Şnorkel Giriş } \\
\text { Alan1 } \\
\left(\mathrm{mm}^{\wedge} 2\right)\end{array}$ & $\begin{array}{c}\text { Kirli Hava } \\
\text { Emiş Borusu } \\
\text { Kalınlığ1 } \\
(\mathrm{mm})\end{array}$ & $\begin{array}{c}\text { Temiz Hava } \\
\text { Emiş Borusu } \\
\text { Kalınlığ1 } \\
(\mathrm{mm})\end{array}$ \\
\hline 1 & $\mathrm{~d}+75$ & $\mathrm{~d}+65$ & $\mathrm{e}+6500$ & $\mathrm{f}+2$ & $\mathrm{f}+2$ \\
\hline 2 & $\mathrm{~d}+75$ & $\mathrm{~d}+70$ & $\mathrm{e}+8000$ & $\mathrm{f}+2$ & $\mathrm{f}+2$ \\
\hline 3 & $\mathrm{~d}+75$ & $\mathrm{~d}+75$ & $\mathrm{e}+9500$ & $\mathrm{f}+3$ & $\mathrm{f}+3$ \\
\hline 4 & $\mathrm{~d}+75$ & $\mathrm{~d}+80$ & $\mathrm{e}+11000$ & $\mathrm{f}+3$ & $\mathrm{f}+3$ \\
\hline 5 & $\mathrm{~d}+80$ & $\mathrm{~d}+65$ & $\mathrm{e}+8000$ & $\mathrm{f}+3$ & $\mathrm{f}+3$ \\
\hline 6 & $\mathrm{~d}+80$ & $\mathrm{~d}+70$ & $\mathrm{e}+6500$ & $\mathrm{f}+3$ & $\mathrm{f}+3$ \\
\hline 7 & $\mathrm{~d}+80$ & $\mathrm{~d}+75$ & $\mathrm{e}+11000$ & $\mathrm{f}+2$ & $\mathrm{f}+2$ \\
\hline 8 & $\mathrm{~d}+80$ & $\mathrm{~d}+80$ & $\mathrm{e}+9500$ & $\mathrm{f}+2$ & $\mathrm{f}+2$ \\
\hline 9 & $\mathrm{~d}+85$ & $\mathrm{~d}+65$ & $\mathrm{e}+9500$ & $\mathrm{f}+2$ & $\mathrm{f}+3$ \\
\hline
\end{tabular}




\begin{tabular}{|c|c|c|c|c|c|}
10 & $d+85$ & $d+70$ & $e+11000$ & $f+3$ & $f+3$ \\
\hline 11 & $d+85$ & $d+75$ & $e+7000$ & $f+3$ & $f+2$ \\
\hline 12 & $d+85$ & $d+80$ & $e+8000$ & $f+3$ & $f+2$ \\
\hline 13 & $d+90$ & $d+65$ & $e+11000$ & $f+3$ & $f+2$ \\
\hline 14 & $d+90$ & $d+70$ & $e+9500$ & $f+3$ & $f+2$ \\
\hline 15 & $d+90$ & $d+75$ & $e+8000$ & $f+2$ & $f+3$ \\
\hline 16 & $d+90$ & $d+80$ & $e+6500$ & $f+2$ & $f+3$ \\
\hline
\end{tabular}

Tablo 4. Karar matrisi

\begin{tabular}{|c|c|c|c|c|c|c|c|c|c|c|c|c|c|c|c|c|}
\hline Konsept & \multirow[t]{2}{*}{1} & \multirow[t]{2}{*}{2} & \multirow[t]{2}{*}{3} & \multirow[t]{2}{*}{4} & \multirow[t]{2}{*}{5} & \multirow[t]{2}{*}{6} & \multirow[t]{2}{*}{7} & \multirow[t]{2}{*}{8} & \multirow[t]{2}{*}{9} & \multirow[t]{2}{*}{10} & \multirow[t]{2}{*}{11} & \multirow[t]{2}{*}{12} & \multirow[t]{2}{*}{13} & \multirow[t]{2}{*}{14} & \multirow[t]{2}{*}{15} & \multirow[t]{2}{*}{16} \\
\hline Kriterler & & & & & & & & & & & & & & & & \\
\hline Emiş ağzından su girmesinin önlenmesi & + & + & + & + & + & + & + & + & - & - & - & - & - & - & - & - \\
\hline Sistemin basınç değiş̧imi & - & + & + & - & - & + & + & - & + & + & - & - & - & + & + & + \\
\hline Kirli hava emiş borusu basınç değişimi & + & + & + & + & + & + & + & + & - & - & - & - & - & - & - & - \\
\hline Temiz hava emiş borusu basınç değişimi & + & + & - & - & + & + & - & - & + & + & - & + & + & + & - & - \\
\hline Filtre kutusu basınç değişimi & $\mathrm{s}$ & $\mathrm{s}$ & $\mathrm{s}$ & $\mathrm{s}$ & $\mathrm{s}$ & $\mathrm{s}$ & $\mathrm{s}$ & $\mathrm{s}$ & $\mathrm{s}$ & $\mathrm{s}$ & $\mathrm{s}$ & $\mathrm{s}$ & $\mathrm{s}$ & $\mathrm{s}$ & $\mathrm{s}$ & $\mathrm{s}$ \\
\hline Sistemin emiş sesi & - & - & + & + & - & - & + & + & + & + & - & - & + & + & - & - \\
\hline Kirli hava emiş borusu emiş sesi & - & - & + & + & - & - & + & + & - & - & + & + & + & - & + & + \\
\hline Temiz hava emiş borusu emiş sesi & - & - & + & + & - & + & + & + & - & - & + & + & - & - & + & + \\
\hline Filtre kutusu emiş sesi & $\mathrm{s}$ & $\mathrm{s}$ & $\mathrm{s}$ & $\mathrm{s}$ & $\mathrm{s}$ & $\mathrm{s}$ & $\mathrm{s}$ & $\mathrm{s}$ & $\mathrm{s}$ & $\mathrm{s}$ & $\mathrm{s}$ & $\mathrm{s}$ & $\mathrm{s}$ & $\mathrm{s}$ & $\mathrm{s}$ & $\mathrm{s}$ \\
\hline Sistemin kolay montaj1 & $\mathrm{s}$ & $\mathrm{s}$ & $\mathrm{s}$ & $\mathrm{s}$ & $\mathrm{s}$ & $\mathrm{s}$ & $\mathrm{s}$ & $\mathrm{s}$ & $\mathrm{s}$ & $\mathrm{s}$ & $\mathrm{s}$ & $\mathrm{s}$ & $\mathrm{s}$ & $\mathrm{s}$ & $\mathrm{s}$ & $\mathrm{s}$ \\
\hline Filtre elemanı(kartuş) değişim kolaylığ1 & $\mathrm{s}$ & $\mathrm{s}$ & $\mathrm{s}$ & $\mathrm{s}$ & $\mathrm{s}$ & $\mathrm{s}$ & $\mathrm{s}$ & $\mathrm{s}$ & $\mathrm{s}$ & $\mathrm{s}$ & $\mathrm{s}$ & $\mathrm{s}$ & $\mathrm{s}$ & $\mathrm{s}$ & $\mathrm{s}$ & $\mathrm{s}$ \\
\hline Filtre elemanına(kartuşa) su ulaşmaması & + & + & + & + & + & + & + & + & - & - & - & + & + & - & - & - \\
\hline Estetik görünüm & + & + & - & - & + & + & - & - & - & - & + & + & + & - & + & + \\
\hline Düzgün hava akış1: çıkış̧üniformluk) & + & - & - & - & + & + & - & - & + & + & - & - & + & + & + & - \\
\hline Bileşenlerin kolay montajı / sökülmesi & $\mathrm{s}$ & $\mathrm{s}$ & $\mathrm{s}$ & $\mathrm{s}$ & $\mathrm{s}$ & $\mathrm{s}$ & $\mathrm{s}$ & $\mathrm{s}$ & $\mathrm{s}$ & $\mathrm{s}$ & $\mathrm{s}$ & $\mathrm{s}$ & $\mathrm{s}$ & $\mathrm{s}$ & $\mathrm{s}$ & $\mathrm{s}$ \\
\hline Hava filtresi kutusunun mekanik direnci & $\mathrm{s}$ & $\mathrm{s}$ & $\mathrm{s}$ & $\mathrm{s}$ & $\mathrm{s}$ & $\mathrm{s}$ & $\mathrm{s}$ & $\mathrm{s}$ & $\mathrm{s}$ & $\mathrm{s}$ & $\mathrm{s}$ & $\mathrm{s}$ & $\mathrm{s}$ & $\mathrm{s}$ & $\mathrm{s}$ & $\mathrm{s}$ \\
\hline Düşük sistem maliyeti & $\mathrm{s}$ & $\mathrm{s}$ & $\mathrm{s}$ & $\mathrm{s}$ & $\mathrm{s}$ & $\mathrm{s}$ & $\mathrm{s}$ & $\mathrm{s}$ & $\mathrm{s}$ & $\mathrm{s}$ & $\mathrm{s}$ & $\mathrm{s}$ & $\mathrm{s}$ & $\mathrm{s}$ & $\mathrm{s}$ & $\mathrm{s}$ \\
\hline Yerel üretim & $\mathrm{s}$ & $\mathrm{s}$ & $\mathrm{s}$ & $\mathrm{s}$ & $\mathrm{s}$ & $\mathrm{s}$ & $\mathrm{s}$ & $\mathrm{s}$ & $\mathrm{s}$ & $\mathrm{s}$ & $\mathrm{s}$ & $\mathrm{s}$ & $\mathrm{s}$ & $\mathrm{s}$ & $\mathrm{s}$ & $\mathrm{s}$ \\
\hline Hava sızdırmazlığı & + & + & - & - & + & + & - & + & - & - & + & + & - & - & + & + \\
\hline Düşük ağırlık & + & - & - & - & + & + & + & - & - & - & + & - & + & - & - & - \\
\hline Az sayıda bileşen & $\mathrm{s}$ & $\mathrm{s}$ & $\mathrm{s}$ & $\mathrm{s}$ & $\mathrm{s}$ & $\mathrm{s}$ & $\mathrm{s}$ & $\mathrm{s}$ & $\mathrm{s}$ & $\mathrm{s}$ & $\mathrm{s}$ & $\mathrm{s}$ & $\mathrm{s}$ & $\mathrm{s}$ & $\mathrm{s}$ & $\mathrm{s}$ \\
\hline Kartuş filtreleme performans1 & + & + & - & - & + & + & - & - & + & + & - & - & + & + & - & - \\
\hline Temiz hava girişi kolaylığı & - & - & + & + & - & - & + & + & + & + & - & - & + & + & - & - \\
\hline S+ & 9 & 8 & 8 & 7 & 9 & 11 & 9 & 8 & 6 & 6 & 5 & 6 & 9 & 6 & 6 & 5 \\
\hline S- & 5 & 6 & 6 & 7 & 5 & 3 & 5 & 6 & 8 & 8 & 9 & 8 & 5 & 8 & 8 & 9 \\
\hline Ss & 9 & 9 & 9 & 9 & 9 & 9 & 9 & 9 & 9 & 9 & 9 & 9 & 9 & 9 & 9 & 9 \\
\hline Toplam & 4 & 2 & 2 & 0 & 4 & 8 & 4 & 2 & -2 & -2 & -4 & -2 & 4 & -2 & -2 & -4 \\
\hline
\end{tabular}

Oluşturulan karar matrisine göre en uygun tasarım seçeneği, en yüksek puanı alan 6 numaralı tasarım konseptidir. Seçilen altı numaralı konseptteki değişkenlerin değerleri aşağıda yer alan Tablo 5 'de görülmektedir. 
Tablo 5. Başlangıç tasarımı

\begin{tabular}{|l|c|c|c|c|c|}
\cline { 2 - 5 } \multicolumn{1}{c|}{} & $\begin{array}{l}\text { Kirli Hava Emiş } \\
\text { Borusu Çapı }(\mathrm{mm})\end{array}$ & $\begin{array}{l}\text { Temiz Hava Emiş } \\
\text { Borusu Çapı }(\mathrm{mm})\end{array}$ & $\begin{array}{l}\text { Şnorkel Giriş } \\
\text { Alanı }\left(\mathrm{mm}^{\wedge} 2\right)\end{array}$ & $\begin{array}{l}\text { Kirli Hava Emiş } \\
\text { Borusu Kalınlığı (mm) }\end{array}$ & $\begin{array}{l}\text { Temiz Hava Emiş } \\
\text { Borusu Kalınlığ }(\mathrm{mm})\end{array}$ \\
\hline Başlangıç Tasarımı & $\mathrm{d}+80$ & $\mathrm{~d}+70$ & $\mathrm{e}+6500$ & $\mathrm{f}+3$ & $\mathrm{f}+3$ \\
\hline
\end{tabular}

Hava emiş sistemi tasarımı için belirlenen değişkenlere göre geliştirilen bu tasarım, başlangıç tasarımıdır. Geliştirilen tasarım, bir sonraki aşamada optimize ederek nihai tasarıma ulaşılmıştır.

\section{Geliştirilen Tasarımın Optimizasyonu}

\subsection{Sistemin kontrol ve gürültü faktörlerinin belirlenmesi}

Optimizasyon aşamasında robuts tasarım yöntemi, diğer bir değişle Taguchi metodu kullanılmış̧ır. Robust tasarım yöntemi ile basınç kaybı ve hava emiş sistemi gürültü seviyesinin hedeflenen değerlerin altında aynı zamanda da en uygun seviyelerde olması amaçlanmıştır [5]. Taguchi metodunda iki önemli faktör bulunmaktadır. Bunlar kontrol ve gürültü faktörleri olarak adlandırılır. Kontrol faktörleri, kontrol altına alınabilen süreç veya tasarım parametrelerini ifade eder. Kontrol edilmesi zor olan süreç veya tasarım parametreleri de gürültü faktörleri olarak adlandırılır. Gürültü faktörleri, tasarım sistemlerinden beklenen performansa olumsuz etki edebilen parametrelerdir. $\mathrm{Bu}$ sebeple de gürültü faktörleri, tasarım süreci içerisine eklenmelidir. Hava emiş sistemindeki kontrol faktörleri, şnorkel parçasının giriş kesit alanının aracın ön tarafına gelebilecek maksimum su yüksekliğinden fazla olması, kirli hava emiş borusu (çapı ve kalınlığı), temiz hava emiş borusu (çapı ve kalınlığı), kirli hava emiş borusu malzemesi, temiz hava emiş borusu malzemesi ve hava filtre kutusu hacmi olarak belirlenmiştir. Hava emiş sistemindeki girdi değeri olarak taze hava debisi, çıktı değerleri olarak hava emiş sesi ve hava emiş sistemi basınç kaybı olarak belirlenmiştir $[2,6]$. Sistemin gürültü parametresi olarak, hava filtre kutusunda yer alan filtre elemanının pozisyonu belirlenmiştir. Hava filtre elemanının düşey konumda, montaj pozisyonundan $10 \mathrm{~mm}$ altında olma durumu ve $10 \mathrm{~mm}$ üzerinde olma durumu en büyük gürültü parametreleri olarak sırasıyla birinci ve ikinci gürültü seviyesi olarak değerlendirilmiştir.
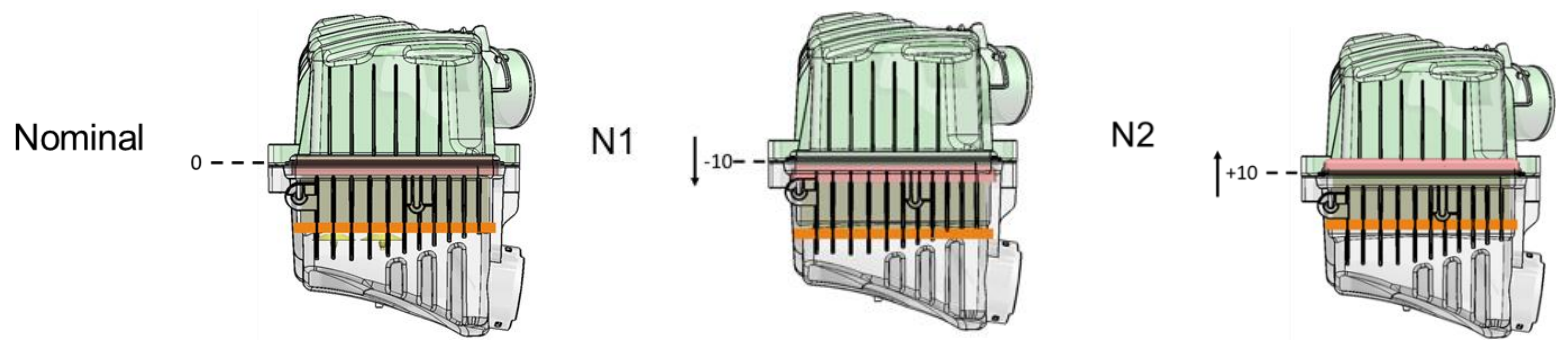

Şekil 3. Hava filtre elemanın gürültü faktörüne göre yerleşimi 


\subsection{Basınç ve emiş sesi dĕgerlerinin bir boyutlu analizler ile elde edilmesi}

Taguchi metodu yaklaşımı ile belirlenen değişkenler kullanılarak Tablo 3'deki gibi 16 farklı tasarım konsepti oluşturulmuştur. Bu konseptlerin kullanılması sonucu oluşacak basınç ve hava emiş ses değerleri, birinci ve ikinci gürültü seviyelerine göre ayrı ayrı bir boyutlu analizlerle elde edilmiştir. Bir boyutlu analizler için GT Suite yazılımı kullanılmıştır. Bulunan basınç ve ses değerleri Tablo 6' da yer almaktadır.

Tablo 6. Basınç kaybı ve hava emişs sesi analiz sonuçları

\begin{tabular}{|c|c|c|c|c|c|c|c|c|c|}
\hline & & & & & & & & & \\
\hline & & & & & & Basınç K & $\mathrm{b}_{1}(\mathrm{kPA})$ & Emiş Se & i (dBA) \\
\hline $\begin{array}{c}\text { Konsept } \\
\text { Numaras1 }\end{array}$ & $\begin{array}{c}\text { Kirli Hava } \\
\text { Emiş Borusu } \\
\text { Çap1 (mm) }\end{array}$ & $\begin{array}{c}\text { Temiz Hava } \\
\text { Emiş Borusu } \\
\text { Çap1 }(\mathrm{mm})\end{array}$ & $\begin{array}{l}\text { Şnorkel Giriş } \\
\text { Alanı }\left(\mathrm{mm}^{\wedge} 2\right)\end{array}$ & $\begin{array}{l}\text { Kirli Hava } \\
\text { Emiş Borusu } \\
\text { Kalınlığ } 1 \\
(\mathrm{~mm}) \\
\end{array}$ & $\begin{array}{c}\text { Temiz Hava } \\
\text { Emiş Borusu } \\
\text { Kalılılğı }(\mathrm{mm})\end{array}$ & N1 & $\mathrm{N} 2$ & N1 & $\mathrm{N} 2$ \\
\hline 1 & $\mathrm{~d}+75$ & $d+65$ & $\mathrm{e}+6500$ & $\mathrm{f}+2$ & $\mathrm{f}+2$ & $a+2,99$ & $\mathrm{a}+4,01$ & $\mathrm{c}+75,40$ & $c+71,76$ \\
\hline 2 & $d+75$ & $\mathrm{~d}+70$ & $e+8000$ & $f+2$ & $f+2$ & $a+2,86$ & $a+3,85$ & $\mathrm{c}+75,14$ & $\mathrm{c}+71,37$ \\
\hline 3 & $d+75$ & $d+75$ & $e+9500$ & $f+3$ & $f+3$ & $a+2,81$ & $a+3,78$ & $\mathrm{c}+74,61$ & $c+77,69$ \\
\hline 4 & $d+75$ & $\mathrm{~d}+80$ & $\mathrm{e}+11000$ & $\mathrm{f}+3$ & $f+3$ & $a+3,24$ & $a+3,87$ & $\mathrm{c}+79,22$ & $\mathrm{c}+76,79$ \\
\hline 5 & $d+80$ & $d+65$ & $\mathrm{e}+8000$ & $f+3$ & $\mathrm{f}+3$ & $\mathrm{a}+3,40$ & $a+3,39$ & $\mathrm{c}+74,27$ & $\mathrm{c}+75,54$ \\
\hline 6 & $\mathrm{~d}+80$ & $d+70$ & $\mathrm{e}+6500$ & $f+3$ & $\mathrm{f}+3$ & $a+2,85$ & $a+3,83$ & $\mathrm{c}+76,37$ & $\mathrm{c}+72,78$ \\
\hline 7 & $\mathrm{~d}+80$ & $d+75$ & $\mathrm{e}+11000$ & $f+2$ & $f+2$ & $a+2,95$ & $a+3,82$ & $\mathrm{c}+83,51$ & $\mathrm{c}+78,06$ \\
\hline 8 & $\mathrm{~d}+80$ & $\mathrm{~d}+80$ & e+9500 & $f+2$ & $\mathrm{f}+2$ & $a+2,98$ & $a+3,61$ & $c+73,85$ & $\mathrm{c}+72,42$ \\
\hline 9 & $d+85$ & $d+65$ & $\mathrm{e}+9500$ & $\mathrm{f}+2$ & $f+3$ & $a+2,94$ & $a+3,93$ & $\mathrm{c}+79,29$ & $\mathrm{c}+75,84$ \\
\hline 10 & $d+85$ & $d+70$ & $e+11000$ & $f+3$ & $f+3$ & $a+2,91$ & $a+3,81$ & $\mathrm{c}+78,83$ & $c+71,62$ \\
\hline 11 & $d+85$ & $d+75$ & $\mathrm{e}+7000$ & $\mathrm{f}+3$ & $\mathrm{f}+2$ & $a+3,07$ & $a+3,68$ & $\mathrm{c}+76,90$ & $\mathrm{c}+75,09$ \\
\hline 12 & $\mathrm{~d}+85$ & $\mathrm{~d}+80$ & $\mathrm{e}+8000$ & $f+3$ & $f+2$ & $a+2,95$ & $a+3,08$ & $c+76,53$ & $\mathrm{c}+77,17$ \\
\hline 13 & $d+90$ & $d+65$ & $\mathrm{e}+11000$ & $\mathrm{f}+3$ & $\mathrm{f}+2$ & $a+3,05$ & $a+3,93$ & $c+86,47$ & $\mathrm{c}+79,53$ \\
\hline 14 & $d+90$ & $d+70$ & $\mathrm{e}+9500$ & $\mathrm{f}+3$ & $\mathrm{f}+2$ & $a+2,80$ & $\mathrm{a}+3,74$ & $c+80,40$ & $\mathrm{c}+76,86$ \\
\hline 15 & $d+90$ & $d+75$ & $\mathrm{e}+8000$ & $\mathrm{f}+2$ & $\mathrm{f}+3$ & $a+2,74$ & $a+3,61$ & $c+80,46$ & $\mathrm{c}+77,15$ \\
\hline 16 & $d+90$ & $\mathrm{~d}+80$ & $\mathrm{e}+6500$ & $\mathrm{f}+2$ & $\mathrm{f}+3$ & $a+2,96$ & $a+3,57$ & $\mathrm{c}+78,72$ & $\mathrm{c}+76,56$ \\
\hline
\end{tabular}

Her bir gürültü seviyesi için elde edilen basınç kaybı ve ses değerleri Minitab programı ile değişkenlere göre analiz edilmiştir. Sinyal- Gürültü oranları (S/N oranı), basınç değerleri için Şekil 4' de, ses değerleri için ise Şekil 5' de görülmektedir. Ayrıca, Şekil 4 ve Şekil 5' te yer alan değişken değerleri, Tablo 2'de yer alan sıraya göredir. Şekil 4 ve Şekil 5' te yer alan grafikler birlikte değerlendirilerek, basınç ve ses grafiklerindeki düşük $\mathrm{S} / \mathrm{N}$ oranına sahip değerler seçilmiştir [5]. Seçilen bu değerler artık optimizasyon sonrası oluşan değerler (optimize edilmiş değerler) olarak adlandırılmaktadır. Optimize edilmiş değerler ile başlangıç değerleri Tablo 7' de bir arada gösterilmiştir. 


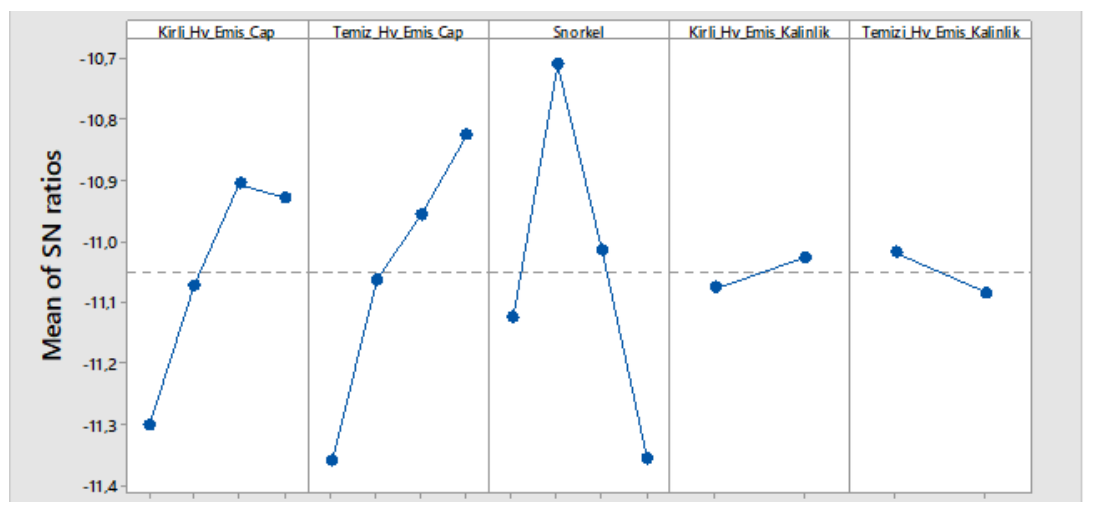

Şekil 4. Basınç kaybı değerlerine göre S-N oranı grafiği

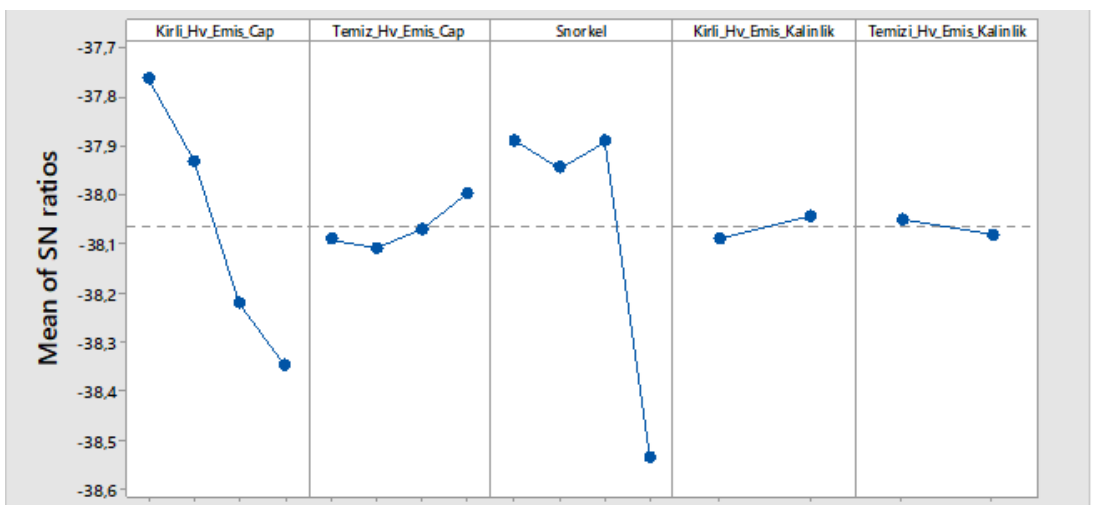

Şekil 5. Emiş sesi değerlerine göre S-N oranı grafiği

Tablo 7. Seçilen tasarımların konseptleri

\begin{tabular}{|l|c|c|c|c|c|}
\cline { 2 - 6 } \multicolumn{1}{c|}{} & $\begin{array}{c}\text { Kirli Hava Emiş Borusu } \\
\text { Çapı }(\mathrm{mm})\end{array}$ & $\begin{array}{c}\text { Temiz Hava } \\
\text { Emiş Borusu } \\
\text { Çapı }(\mathrm{mm})\end{array}$ & $\begin{array}{c}\text { Şnorkel Giriş̧ } \\
\text { Alanı }\left(\mathrm{mm}^{\wedge} 2\right)\end{array}$ & $\begin{array}{c}\text { Kirli Hava } \\
\text { Emiş Borusu } \\
\text { Kalınlığ } 1 \\
(\mathrm{~mm})\end{array}$ & $\begin{array}{c}\text { Temiz Hava } \\
\text { Emiş Borusu } \\
\text { Kalınlığ1 } \\
(\mathrm{mm})\end{array}$ \\
\hline Başlangıç Tasarımı & $\mathrm{d}+80$ & $\mathrm{~d}+70$ & $\mathrm{e}+6500$ & $\mathrm{f}+3$ & $\mathrm{f}+3$ \\
\hline Optimize Edilmiş Nihai Tasarım & $\mathrm{d}+90$ & $\mathrm{~d}+65$ & $\mathrm{e}+11000$ & $\mathrm{f}+2$ & $\mathrm{f}+3$ \\
\hline
\end{tabular}

Başlangıç değerleri ile oluşturulan tasarım ile optimizasyon sonucu oluşan nihai tasarımların, basınç kaybı ve ses değerleri için S/N oranları Minitab programı ile elde edilerek Tablo 8'de gösterilmiştir. Geri basınç için yaklaşık 1, emiş sesi için de 1.9 şeklinde oluşan $\mathrm{S} / \mathrm{N}$ oranı düşüşü, sistemin ilk tasarıma göre optimize edilmiş tasarımda iyileştiğini matematiksel olarak da göstermektedir. 
Tablo 8. Seçilen tasarım konseptlerinin $\mathrm{S} / \mathrm{N}$ oranları

\begin{tabular}{|l|c|c|}
\cline { 2 - 3 } \multicolumn{1}{c|}{} & $\begin{array}{c}\text { Basınç Kaybı } \\
\text { S/N Oranı }\end{array}$ & $\begin{array}{c}\text { Emiş Sesi } \\
\text { S/N Oranı }\end{array}$ \\
\hline Başlangıç Tasarımı & $-10,3506$ & $-38,1921$ \\
\hline Optimize Edilmiş Nihai Tasarım & $-11,3573$ & $-40,1874$ \\
\hline Fark $(\Delta)$ & $-1,0067$ & $-1,9953$ \\
\hline
\end{tabular}

\section{Optimize Edilmiş Tasarımın Doğrulanması}

Optimize edilmiş tasarımın ilk olarak basınç kaybı ve ses kaybı hedef değerlerine göre değerlendirilmesi gerekmektedir. Basınç kaybı ve emiş sesi değerleri ilk olarak bir boyutlu analiz yardımıyla yapılmıştır. Ardından basınç kaybı değeri CFD ile de değerlendirilmiştir.

Çevre parçalar ile hava emiş sistemi arasında olması gereken yakınlıklar ve şnorkel ağzının maksimum su seviyesinden yüksekliği aracın diğer kompenentlerine göre kontrol edilmiştir. Mesafeler hedeflenen değerleri karşılamaktadır. Görseller araç için özel olduğundan bu çalışmada paylaşılmamıştır.

Optimize edilen tasarımın ve başlangıç tasarımının, bir boyutlu analizlerle oluşturulan basınç kaybı değerleri Şekil 6 ile gösterilmiştir.
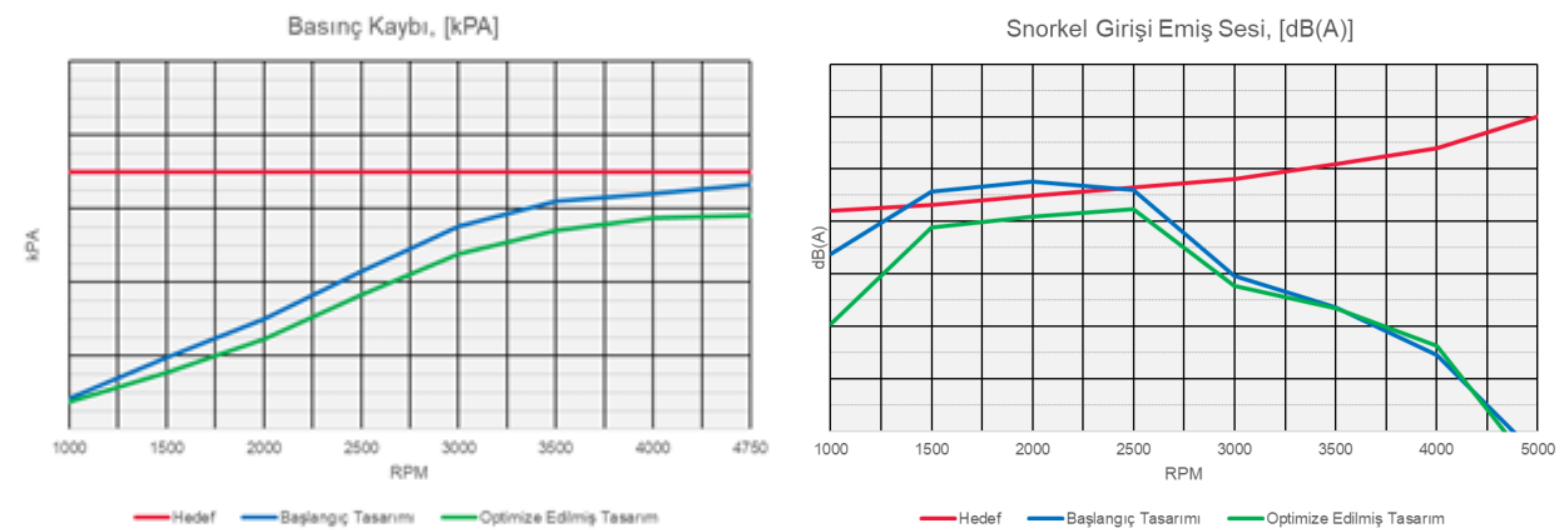

Şekil 6. Başlangıç ve optimize edilmiş (nihai) tasarımın basınç kayıpları ve emiş sesleri

Şekil 6'da da görüldüğü gibi optimize edilen tasarım, basınç kaybı ve emiş sesi değerleri bakımından hedef değerlerinin altındadır ve başlangıç tasarımına göre daha iyi konumda yer almaktadır. Ayrıca hem basınç kaybı hem de emiş sesi bakımından hedeflenen değerlerin altında olunması sistemin bu iki temel kriter açısından doğrulanmasıdır.

Diğer bir doğrulama da basınç kaybının CFD (Star CCM yazılımı) analizi ile hesaplanmasıdır. 
Analize sokulan tasarımın 3D modeli Şekil 7'de gösterilmiştir. Bir boyutlu analize göre, CFD analizlerinin hassas sonuçlar vermesi beklenen bir durumdur. Bu sebeple de CFD analizlerine göre basınç kaybı, bir boyutlu analizlere göre $0.8 \mathrm{kPA}$ daha düşük hesaplanmıştır.

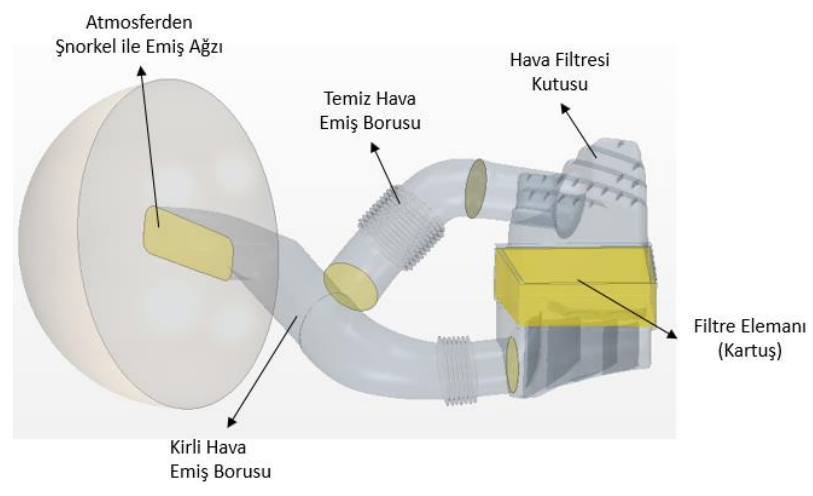

Şekil 7. Tasarımın analiz modeli

Akış ile ilgili diğer bir kriter de motor girişinde akış ünifomluk indeksinin a+0,92'den büyük olmasıdır. Hava emiş sisteminin tamamlandığı ve motora giriş yapılan kesitte ünifomluk indeksi hedeflenen değerden daha iyi bir seviyede olup a $+0,93$ olarak bulunmuştur. Uniformluk endeksinin hesaplandığı kesit Şekil 8 ile gösterilmiştir.

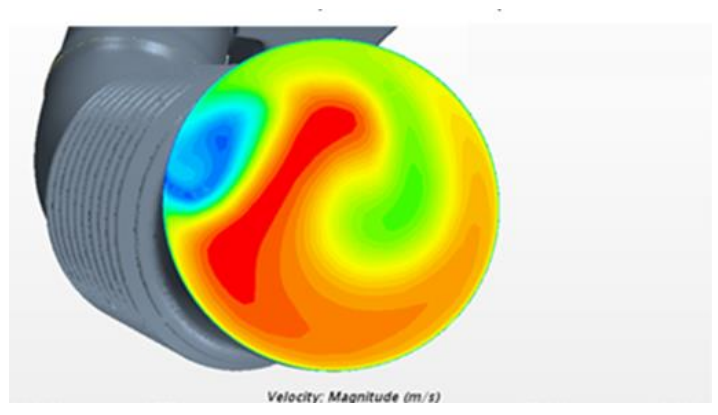

Şekil 8. Uniformluk indeksi kesiti

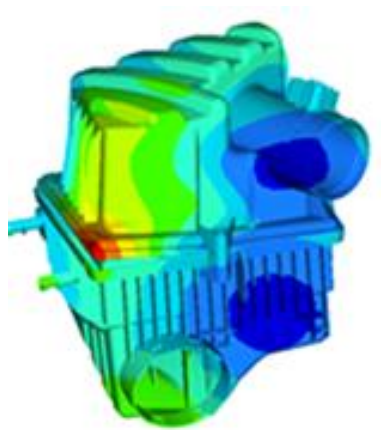

Şekil 9. Hava filtre kutusu- 1. Mod onucu

Bir sonraki aşamada, hava emiş filtre kutusunun yapısal dayanımının incelenmiştir. Optistruct programı ile yapılan modal analiz sonucu Şekil 9'de gösterilmiştir. Analiz sonuçlarına göre 1. modda hedef değer olan b+280 Hz'in üzerine çıkıldığı, sonuç olarak b+304 Hz elde edildiği anlaşıllmıştır.

\section{Sonuç}

Ticari bir araç için hava emiş sistemi Altı Sigma Tasarım (DFSS) metodolojisi kullanılarak bu çalışma yarımıyla oluşturulmuştur. Sistemden beklenen ihtiyaçların karşılanması için farklı tasarım konseptleri belirlenmiştir. Tasarım konseptleri kendi aralarında değerlendirilerek, en uygun olan 
konsept seçilmiştir. Belirlenen seçenek Taguchi yaklaşımı yardımıyla optimize edilerek nihai tasarım oluşturulmuştur. Oluşturulan nihai tasarım, tasarım için belirlenen hedeflere göre sanal analizler yardımıyla doğrulanmıştır.

Oluşturulan nihai tasarım, hedef değerlere ve başlangıç tasarıma göre basınç kaybı ve emiş sesi kriterlerine göre daha iyi bir noktaya çekilmiştir. DFSS sistematiği kullanılarak, tasarım için önemli parametreler kontrol altına alınmıştır. Parametrelerin kendi aralarındaki ilişkileri esas alınarak, oluşturulan nihai sistem üzerindeki etkileri belirlenmiştir. Bu sayede de oluşturulan konseptler içinden en uygun olanı seçilebilmiştir.

\section{Kaynaklar}

[1] Lee H, Yang B, Cho H. Air flow analysis of snorkel in vehicle intake system. International Journal of Applied Engineering Research 2017; ISSN 0973-4562- Volume 12.

[2] $\mathrm{Xu} \mathrm{C}, \mathrm{Cho} \mathrm{H}$. Analysis on the noise reduction of engine with air intake resonator in engine intake system. International Journal of Engineering and Technology 2018; 10(1):149-153.

[3] Chen J, Li Y, Cox R. Taguchi-based six sigma approach to optimize plasma cutting process: an industrial case study. The International Journal of Advanced Manufacturing Technology 2002; Volume 41, Issue 7-8, pp 760-769.

[4] Burge S. Pugh matrix (PM). The Systems Engineering Tool Box; 2009

[5] URL1: Methods and formulas for Analyze Taguchi Design, Minitab 19 Support, https://support.minitab.com/.

[6] Ramasamy D, Zamri M, Mahendran S, Vijayan S. Design optimization of air intake system (ais) of 1.61 engine by adding guide vane. International Multiconference of Engineers and Computer Scientists Hong Kong.Vol 2; 2010. 